\title{
Optimising a retention strategy with young people for BRIGHTLIGHT, a longitudinal cohort study examining the value of specialist cancer care for young people
}

\author{
${ }^{1}$ Rachel M Taylor PhD (rtaylor13@nhs.net), ${ }^{1}$ Natasha Aslam MSc \\ (Natasha.aslam@uclh.nhs.uk), 2Sarah Lea BSc (sarah.lea@canterbury.ac.uk), ${ }^{1}$ Jeremy S \\ Whelan MD (Jeremy.whelan@uclh.nhs.uk), 1'Lorna A Fern PhD (lorna.fern@ncri.org.uk) \\ ${ }^{1}$ Cancer Division, University College London Hospitals NHS Foundation Trust, London, UK \\ ${ }^{2}$ Faculty of Health and Wellbeing, Canterbury Christ Church University, Kent, UK \\ Corresponding author: Dr Lorna Fern PhD, Cancer Division, University College London \\ Hospitals NHS Foundation Trust, $1^{\text {st }}$ Floor Central, 250 Euston Rd, London NW1 2PG United \\ Kingdom. Tel: +44 (0) 203447 7199; Email lorna.fern@ncri.org.uk
}

Running head: Developing a retention plan for a longitudinal cohort study

Keywords: patient involvement/engagement, retention, BRIGHTLIGHT, longitudinal research, cohort study

Words $=3,010 / 3000$ 


\begin{abstract}

\section{Purpose:}

To maximise retention of participants in a longitudinal cohort study, we sought to understand young peoples' views about barriers and facilitators to continuing study participation.

\section{Methods:}

Ten young people with a previous cancer diagnosis aged 15-24 participated in a one day workshop. The workshop used participatory methodology consisting of three exercises: role play/scene setting; force field analysis of research participation in small groups; focus group discussion. A final prioritisation exercise was administered individually after the workshop.
\end{abstract}

\title{
Results:
}

Twenty-four barriers to maintaining participation were summarised in five themes: life commitments; concerns specific to the study; emotional barriers; practical barriers and other reasons. The top three specific barriers were: not a priority/other things are more important; too time consuming and forgetting/memory. The top three facilitators for participation were: wishing to help other young people; giving back to the cancer community and honouring an initial commitment to participation. The top three suggested solutions to encourage continued participation were: reminder text message or email before each survey to check preferred method of delivery; breaking up the online survey into modules to make completion less overwhelming; and consolidation of study information in one location.

\section{Conclusion:}

Involving young people in designing a retention strategy for young people with cancer has informed the BRIGHTLIGHT retention strategy. Patient and public involvement is imperative for successful research but measuring impact is challenging. The success of implementing the changes to optimise retention was shown in the increase in retention in Wave 3 from $30 \%$ to final participation of $58 \%$. 


\section{BACKGROUND}

There is increasing evidence that young people are under-represented in cancer clinical trials and this may be related to lesser improvements in outcomes for this group when compared to children and older adults [1-5]. Consequently, increasing recruitment to cancer studies for young people has become a priority in many adolescent and young adult initiatives. However, little, if no attention has been given to the retention into research studies. Retention is essential for data completeness in follow up for both clinical trials and cohort studies.

As such, two key factors are judged to be necessary for successful cohort studies: initial recruitment of participants to establish the cohort and then subsequent retention throughout the study period. Many recommendations have been proposed to improve recruitment and retention [6,7] and they are often discussed as similar entities but in practice require different approaches to achieve success. Notably, recruitment is often led predominantly by recruiters such as healthcare professionals in multiple participating institutions, who may act as gatekeepers to potential patients [8-10] in contrast to study participant retention where the core research team are likely to have the leading role.

Cancer patients are reported to be highly motivated to join research studies [11]. Although motivation levels may be high at the outset of study participation, motivation may not be maintained, resulting in attrition of study populations [6, 7]. The loss of subjects may increase research costs, threaten validity of results and delay or prevent meaningful outcomes [12].

Retention strategies are therefore desirable to maintain participant engagement. Reviews of retention strategies for cohort studies [7] and clinical trials [6] consistently found incentivisation to be the most effective retention strategy. Most cohort studies reporting use of incentives are from North America or, if the studies were based in United Kingdom (UK), involve non-health populations [7].. Regulatory processes for health research in the UK do not easily permit incentivisation as it is viewed to be potentially coercive [13]. An additional challenge for retaining young people in research is accommodating their unique psychosocial needs and life stage commitments which create specific challenges to research participation. This must be taken into account in the design and conduct of research with young people [14]. [2].[11].

BRIGHTLIGHT (NIHR RP-PG-1209-10013) is a national longitudinal cohort study evaluating specialist cancer care for young people aged $13-24$ years $[15,16]$. The study follows young people aged 13-24 at cancer diagnosis for three years and data collection occurs over five times points $[15,16]$ (www.brightlightstudy.com). Young people have been integral to BRIGHTLIGHT; prior to funding young people were involved in the feasibility work $[17,18]$, helped implement the protocol $[15,16]$ and advised on study related issues $[10]$ and readers 
are referred to our publications $[10,15,16]$. BRIGHTLIGHT aimed to recruit 2012 young people over 18 months and while a number of strategies were employed to optimise recruitment $[10,19]$, it was below the anticipated target of 2,012 . A number of barriers existed to recruitment [10] but study uptake was higher than anticipated (80\% versus 60\%) and retention at Wave 2 an impressive 69\%. However, we noted early on that uptake at Wave 3 was not in parallel to Wave 2 retention figures and therefore we decided to review our retention strategy so we could implement prompt changes.

From the outset, our retention strategy was developed based on recommendations derived from the literature and from our experience of working with young people and specifically what young people had told us during feasibility and set up of BRIGHTLIGHT $[15,16]$. Table 1 illustrates the retention strategies we adopted and why we felt they were particularly relevant for our population. . Having identified that typical recruitment strategies may be less effective for young people, [10] we recognised the importance of examining their unique needs to maximise retention and felt that young people themselves were best placed to describe these to us.

The BRIGHTLIGHT Young Advisory Panel (YAP) is a group of 20 young people convened to work alongside BRIGHTLIGHT researchers to optimise study design and delivery. They will also play a pivotal role in dissemination

(http://www.brightlightstudy.com/event/november-2014-brightlight-update-at-fysot/).

\section{AIM}

To maximise retention of participants in a longitudinal cohort study we wished to understand young peoples' views about barriers and facilitators to continued study participation.

\section{METHODS}

\section{Participants, setting and recruitment}

Data were collected from a workshop held in a non-clinical venue attended by members of the YAP $[10,15,17]$. The workshop was advertised on the YAP Facebook page and by newsletter sent to the BRIGHTLIGHT Cohort of approximately 950 young people. Having members of the YAP who are and are not in BRIGHTLIGHT has been invaluable for acquiring the opinions of those presented with a hypothetical scenario as well as those in the study. Being able to seek the advice from young people nationally has the added benefit of ensuring national representation, as well as a range of ages, cancer types and experiences of care. In line with national guidelines for user involvement in the UK, the YAP received a $£ 30$ voucher. Travel costs and refreshments were also provided. 
Twenty three young people expressed interest in attending the workshop. Of those, ten young people attended, median age 21.5 (range 15-25) years, six female and four male. Young people were diagnosed median age 20 (range 13-23) years with Hodgkins lymphoma $(n=5)$, osteosarcoma, acute myeloid leukaemia, testicular, brain and thyroid cancer. Three were still on treatment. Two researchers (LF, RT) and one Teenage and Young Adult cancer nurse (SL) facilitated the workshop.

\section{Ethics}

BRIGHTLIGHT is approved by an NHS Research Ethics Committee. Prior to the workshop, participants were sent information about the day. Written consent was obtained from all attendees after a detailed description of what the day would entail. Young people were made aware they were free to leave the workshop at any time. After the workshop, each young person was contacted by a member of the research team to ensure the workshop had not resulted in any distress.

\section{Workshop format}

Using established formats $[10,15,17]$, young people were given an opportunity to get to know each other prior to commencing activities. The day was structured around three exercises to explore retention of study participants specifically at the fourth and fifth waves of data collection, when young people are two and three years after diagnosis. The day was interspersed with short breaks and time for individual reflections.

\section{Exercise 1: Role Play and Presentation}

The study team re-enacted a stakeholder meeting held between the research funder, the chief investigator and workstream leads. The purpose of this scenario was to convey the discussions and questions asked by the funder on the progress of the study so young people would be aware of the importance of recruitment and retention (Table 2). Simultaneously, it provided an opportunity to update the workshop attendees of the research objectives and how their previous involvement had impacted change.

A slide presentation was used to present the study structure, photographs and results of previous workshops involving young people (http://www.brightlightstudy.com/userinvolvement/), including actions taken on their previous recommendations [10, 17]. A short discussion was then held to address any questions from the YAP. This allowed the research team to reinforce the objectives of the workshop and ensure young people were clear what their involvement would entail and how it could contribute to improving the study.

\section{Exercise 2: Force Field Analysis}

Young people worked in small groups to consider barriers to survey participation and possible approaches to overcome these. The study team utilised a decision making tool named 'Force Field Analysis', commonly used in business, to list, discuss and consider 
variables for and against implementing change [20]. It is a systematic and transparent model made up of three stages: evaluation function; analysis function; and project planning, useful for identifying 'restraining' and 'driving forces'. Groups were instructed to consider the restraining forces which would limit young people's participation in the study and the driving forces which would include their motives for continuing. The groups were asked to consider both sets of variables and then suggest interventions or solutions that the study team could adopt.

Groups were provided with a large poster of a bridge used to represent two time points of the study, 2014 and 2017. Within the 2014 box, groups were asked to list the restraining forces that may limit their participation in future surveys. Similarly, in the second box representing the endpoint of data collection in 2017, groups were asked to list reasons which would motivate young people to complete all or most the surveys (Figure 2a). Lastly the space in the middle was used to list the interventions that might support the 'crossing of the bridge' successfully from 2014 to 2017 . The concept of a 'bridge crossing' was used in a previous workshop and found to be easily understandable by young people and so was adapted for this study [15]. Following this activity young people reconvened to feedback their results and comment on the results of the other groups.

\section{Exercise 3: BRIGHTLIGHT online presence}

We sought feedback from participants on the content and structure of the study website. Our earlier work highlighted the benefit of a website to engage study participants [10] and the BRIGHTLIGHT website is the primary method of communicating both with young people and other stakeholders. However, concerns had arisen about its appearance and content.

On a large screen a researcher presented the current website. Groups were given laptops and asked to look at websites they often visited. We provided a list of questions to help list appealing features such as branding and navigation (see box 1 ).

The participants were asked to select three websites they liked and discuss in their groups how the BRIGHTLIGHT website could be improved. The groups reconvened to feedback their discussions and also offered individual reflections of the current website and which features should be enhanced or new items introduced to improve its value.

\section{RESULTS}

\section{Exercise 1: Role Play and Presentation}

An interactive discussion followed the role play and after the presentation few questions emerged about the study. It was apparent most young people had a good understanding of BRIGHTLIGHT, including its objectives and the importance of recruitment and retention. 


\section{Exercise 2: Force Field Analysis}

Young people discussed and listed potential reasons for attrition during study progression, reasons for continuation and lastly how the study team could implement strategies to improve retention (Figure $2 \mathrm{~b}$ and Table 3 ).

Barriers to participation: Young people discussed several reasons why those in the study may not continue with subsequent stages of the study. Five themes emerged:

1) Life commitments e.g., school or work, more important/pressing things to do

2) Study Specific barriers e.g., no incentives, repetition and too time consuming

3) Emotional barriers e.g., unwillingness to revisit cancer experience, not wanting to talk about issues

4) Practical barriers e.g., changing telephone number, moving house

5) Other reasons e.g., memory and physical health

Reasons to continue: Reasons to continue with the study stemmed mainly from the discussions the YAP had about the benefits of BRIGHTLIGHT to the wider young cancer community. They perceived this as one of the most important reasons for the Cohort members to continue with the surveys as participation could help influence TYA cancer care. This notion of helping other young people with cancer was a recurring reason which presented in a number of ways, for example 'prevent others from a bad experience' and 'making a difference and enabling others to be helped'.

Another common reason for continuation with the study was for the personal sense of achievement it would bring to those completing BRIGHTLIGHT and the commitment they had shown over the course of the study (Table 3).

Interventions to facilitate continuation: By considering both the list of barriers to participation and reasons to continue, the YAP proposed practical solutions, including using a wider range of engagement and interaction methods with the Cohort e.g. Instagram. Amongst this list were changes such as shortening the lengthy correspondence, which invites participants to the next survey (Table 3).

\section{Exercise 3: Methods to engage study participants}

The groups reflected on the current website and how this could be improved to better appeal with the Cohort. The recommendation for a complete website re-design was unanimous. Collectively the group felt the existing design and 'feel' of the website did not attract young users and should adopt a less text-heavy and 'fresher' look. As young users they felt most information they wanted should be kept short and easily available through simple navigation instead of being spread across different pages. The video information on the current website was well received and was a preferred method of relaying information in place of text. 


\section{Post workshop consultation:}

After the workshop, we sought feedback from the user panel by an online survey. This enabled the research team to collect individual reflections of the force field activity and get young people to independently rate their top three barriers, facilitators, and interventions the study team should consider adopting to optimise retention.

The top three barriers were:

1) Not a priority/ other things are more important ( $n=6 ; 20 \%)$

2) Too time consuming $(n=5 ; 16.7 \%)$

3) Forget/memory ( $n=5 ; 16.7 \%)$

The full list of options can be seen in Figure 3.

From this task it emerged the three most frequently ranked reasons to take part were helping others ( $n=6 ; 26.7 \%)$, giving back to the cancer community $(n=5 ; 16.7 \%)$ and commitment ( $n=4 ; 13.3 \%)$. The three most highly ranked solutions to increase retention, comprised of a reminder text or email before each survey to check preferred method of delivery ( $n=7 ; 23.3 \%)$, followed by breaking up the online version of the BRIGHTLIGHT survey (main method of data collection) into modules to make completion less overwhelming ( $n=7 ; 23.3 \%)$ and for all information to be consolidated in once place on line, for example in an app ( $n=6 ; 20 \%)$. Feedback indicated the activities enjoyed most by the group included the bridge activity, followed by the opportunity to provide input into the website and lastly meeting other young people.

\section{DISCUSSION}

To our knowledge this is the first time young people with cancer have been actively consulted to assist in the development of a longitudinal study retention strategy. While the majority of the results supported existing recommendations [6, 7, 14, 21-25] and had already been implemented in BRIGHTLIGHT, confirming acceptability and preferences of young people is important to identify where resources should be targeted to optimise retention. Based on the workshop a number of changes were made to our existing strategy (Box 2).

The most common solution to improve retention was text message/email before each survey. As shown in Table 1, contact prior to each wave of data collection was already used. This is a combination of postal notification and email depending on young people's preference. As the study progressed and young people are 2 to 3 years post-diagnosis, we identified the challenge of keeping track of young people as they moved on from their cancer treatment back to work, college and university. Even with prompts, young people 
rarely updated us with their change of address and we were dependent on their secondary care providers to keep us informed of change of address. However, within 2 to 3 years following diagnosis many young people often had minimal contact with their cancer inpatient team leaving us to rely on their primary care providers. Young people represent the most mobile populations in the UK [26] so often they had moved and/or changed their primary care provider. We were therefore unable to check young people were still alive and send them notification of the next survey by post; we did not want to send mail to young people who had passed away or confidential mail to addresses where young people no longer lived. Young people were still invited to participate through email (on the assumption the email address would be inaccessible to others) but this was not an optimal retention strategy.

Having accurate contact information is reported as key to retention into longitudinal studies $[14,21,24,27,28]$. The UK has centralised healthcare informatics (http://digital.nhs.uk/) so it is possible to trace any patient with an NHS identifier number to obtain up-to-date address and details of whether they are still alive. We obtained additional regulatory approvals for this method and the first linkage made on the whole Cohort identified 113 out of 1,126 young people had died, compared to the 62 we were previously aware of, and that addresses of 305 young people had changed.

The second most popular solution was to break up the online survey into modules. This was already in place but may have reflected the traditional computer-assisted-web-interviewing (CAWI) format being used and not the 'app' style applications young people are more familiar with. This is also related to the third suggestion: less paper - all information consolidated in one place. All documents have always been available through the website (www.brightlightstudy.com), which was co-developed with young people [10]. However, from the point of study funding in 2011 until now, internet technology has advanced at an unprecedented rate and the website was now perceived as outdated by young people. As healthcare professionals working in a heavily-regulated environment it is often a challenge to keep up with technology and ensure methods of communication are in line with those currently being used by young people. Our experience has demonstrated a yearly shift in social media preferences. From August 2012 permission to host a BRIGHTLIGHT Facebook page to be accessed on NHS computers within our host Trust took eight months to approve and was then only granted as a closed group with young people we had physically met and who had filled out a number of consent and code of conduct forms. When we tried to reengage the Group who had suggested the Facebook page a number of them had moved on and the opportunity for continual engagement had been lost. We launched our Twitter campaign in 2014, as a public facing communication tool and as a recruitment and retention intervention. In 2015, we revised the website in response to requests from the YAP and in 2016 we launched an Instagram account at the recommendation of young people. Digital media requires an informed communications contact, which research teams may not have. 
Finally, although not mentioned in young people's top three, a topic discussed in the workshop (Table 3) and fed back by our telephone survey interviewers is that young people do not always want to revisit their cancer story. We initially had some awareness of this and the survey is designed to only ask questions relevant to the young person's current life situation [16]. Therefore, when preparing our postcards/newsletters to feedback results to young people at $2 / 3$ years after diagnosis we ensure they are related to non-cancer issues for example, sex and relationships. Based on the YAP's advice we will provide 'short, sharp information' to reinforce this fact.

This study had a number of limitations which includes a single focus group of self-selected research-aware young people and may not represent the opinions of other young people. Additionally, the focus of the workshop was on cohort studies and therefore the recommendations may not be applicable to clinical trials. Despite this, young people have identified the retention strategies that are most acceptable to them and can act as a guide to direct resources in future research to maximise retention.

Consulting young people on measures to improve retention has been invaluable for affirming what we are currently doing but also ensuring this is refined to reflect young people's preferences. Similar to our previous work exploring reasons why young people would want to participate in BRIGHTLIGHT [15], altruism and 'giving back' was a feature of conversations within the workshop. However, when facing the transition from cancer patient into living after cancer whilst simultaneously transitioning from a teenager into early adulthood, participation in longitudinal research is challenging. Based on the results of this workshop our recommendations for retaining young people in a cohort study are outlined in Box 3. The success of implementing the changes to optimise retention were shown in the increase in retention in Wave 3 from $30 \%$ to final participation of $58 \%$ 


\section{Acknowledgements}

We would like to thank the members of the Young Advisory Panel who attended the workshop (Natasha Tollett, Nicola Johnson, Sarah Louise Metcalf, Mariia Onasanya, Stephanie Still, Jonathon Wheeler, Andrew Davies, Matthew Burgess, Zeena Beale, Joshua Lerner); and Anita Solanki, former BRIGHTLIGHT Patient \& Public Involvement Manager for maintaining the Cohort.

This paper presents independent research funded by the National Institute for Health Research (NIHR) under its Programme Grants for Applied Research Programme (Grant Reference Number RP-PG-1209-10013). The views expressed are those of the author(s) and not necessarily those of the NHS, the NIHR or the Department of Health. The BRIGHTLIGHT Team acknowledges the support of the NIHR, through the Cancer Research Network. LAF is funded by Teenage Cancer Trust who had no input into study design, analysis or write up.

This manuscript is dedicated to the memory of Matthew Cook, valued member of the National Cancer Research Institutes Teenage and Young Adult Clinical Studies Group and BRIGHTLIGHT YAP.

\section{Author Disclosure Statement}

The authors Rachel Taylor, Sarah Lea, Jeremy Whelan and Natasha Aslam have no conflicts of interest to declare. Lorna Fern is funded by Teenage Cancer Trust. 


\section{References}

1. Bleyer A, Montello M, Budd T, et al. National survival trends of young adults with sarcoma: lack of progress is associated with lack of clinical trial participation. Cancer 2005;103:1891-7.

2. Fern LA, Lewandowski J, Coxon KM, et al. Available, accessible, aware, appropriate and acceptable: a strategy for improving participation of teenagers and young adults in cancer clinical trials, Lancet Oncology 2014;15:e341-50.

3. Ferrari A, Dama E, Pession A, et al. Adolescents with cancer in Italy: entry into the national cooperative paediatric oncology group AIEOP trials. Eur J Cancer 2009;45:328-34.

4. Hay AE, Rae C, Fraser GA, et al. Accrual of adolescents and young adults with cancer to clinical trials. Current Oncology 2016;23:e81-5.

5. Mitchell AE, Scarcella DL, Rigutto GL, et al. Cancer in adolescents and young adults: treatment and outcome in Victoria. Med J Aust 2004;180:59-62.

6. Brueton VC, Tierney JF, Stenning S, et al. Strategies to improve retention in randomised trials: a Cochrane systematic review and meta-analysis, BMJ Open 2014;4:e003821.

7. Booker $\mathrm{CL}$, Harding $\mathrm{S}$, Benzeval $\mathrm{M}$. A systematic review of the effect of retention methods in population-based cohort studies, BMC Public Health 2011;11:249.

8. McDonald AM, Knight RC, Campbell MK, et al. What influences recruitment to randomised controlled trials? A review of trials funded by two UK funding agencies, Trials 2006;7:9-.

9. Ross $S$, Grant A, Counsell C, et al. Barriers to participation in randomised controlled trials: a systematic review, J Clin Epidemiol 1999;52:1143-56.

10. Taylor RM, Solanki A, Aslam N, et al. A participatory study of teenagers and young adults views on access and participation in cancer research, European Journal of Oncology Nursing 2016;20:156-64.

11. Pearce S, Brownsdon A, Fern L, et al. The perceptions of teenagers, young adults and professionals in the participation of bone cancer clinical trials, European Journal of Cancer Care 2016.

12. Bower $P$, Brueton $V$, Gamble $C$, et al. Interventions to improve recruitment and retention in clinical trials: a survey and workshop to assess current practice and future priorities, Trials [Electronic Resource] 2014;15:399.

13. Health Research Authority. HRA Ethics Guidance: payments and incentives in research. 2014.

14. Hanna KM, Scott LL, Schmidt KK. Retention strategies in longitudinal studies with emerging adults. Clinical Nurse Specialist 2014;28:41-5.

15. Taylor RM, Mohain J, Gibson F, et al. Novel participatory methods of involving patients in research: naming and branding a longitudinal cohort study, BRIGHTLIGHT, BMC Medical Research Methodology 2015;15:20.

16. Taylor RM, Fern LA, Solanki A, et al. Development and validation of the BRIGHTLIGHT Survey, a patient-reported experience measure for young people with cancer, Health and Quality of Life Outcomes 2015;13:107.

17. Fern L, Taylor RM, Whelan J, et al. 'The art of age appropriate care': using participatory research to describe young people's experience of cancer, Cancer Nursing. 2013;36:E27-38. 
18. Taylor RM, Fern L, Millington $\mathrm{H}$, et al. "Your place or mine?" Priorities for a specialist teenage and young adult (TYA) cancer unit: disparity between TYA and professional perceptions, Journal of Adolescent and Young Adult Oncology 2011;1:145-51.

19. Taylor RM, Fern LA, Aslam N, et al. Direct access to potential research participants for a cohort study using a confidentiality waiver included in UK National Health Service legal statutes, BMJ Open 2016;6:e011847.

20. Lewin K. Field theory in social science. New York: Harper and Row 1951.

21. Bonk J. A road map for the recruitment and retention of older adult participants for longitudinal studies, J Am Geriatr Soc 2010;58:S303-7.

22. Ely $B$, Coleman $C$. Recruitment and retention of children in longitudinal research. Journal for Specialists in Pediatric Nursing: JSPN 2007;12:199-202.

23. Khoo SK, O'Neill S, Travers C, et al. Age-related changes relevant to health in women: design, recruitment, and retention strategies for the Longitudinal Assessment of Women (LAW) study. Journal of Women's Health 2008;17:135-46.

24. Leonard NR, Lester P, Rotheram-Borus MJ, et al. Successful recruitment and retention of participants in longitudinal behavioral research, AIDS Education \& Prevention 2003;15:269-81.

25. Motzer SA, Moseley JR, Lewis FM. Recruitment and retention of families in clinical trials with longitudinal designs. West J Nurs Res 1997;19:314-33.

26. Office of National Statistics. Statistical Bulletin: Internal migration, England and Wales, year ending June 2015. 2016.

27. Seed $M$, Juarez $M$, Alnatour $R$. Improving recruitment and retention rates in preventive longitudinal research with adolescent mothers. Journal of Child \& Adolescent Psychiatric Nursing 2009;22:150-3.

28. Simkin LS, Hirsch L, Radosh A, et al. Strategies to maximize retention of a sample of young adolescents in a longitudinal evaluation of Healthy \& Alive!. J Sch Health 2000;70:286-91.

29. Nicholson LM, Schwirian PM, Klein EG, et al. Recruitment and retention strategies in longitudinal clinical studies with low-income populations. Contemporary Clinical Trials 2011;32:353-62.

30. Cantrell MA, Conte $\mathrm{T}$, Hudson $\mathrm{M}$, et al. Recruitment and retention of older adolescent and young adult female survivors of childhood cancer in longitudinal research. Oncol Nurs Forum 2012;39:483-90.

31. Smith JA, Wilde MH, Brasch J. Internet recruitment and retention for a 6 months' longitudinal study. Journal of Nursing Scholarship 2012;44:165-70. 
Table 1: Retention strategies suggested in the literature and how they were incorporated into the design of BRIGHTLIGHT

\begin{tabular}{|c|c|c|}
\hline Published retention strategy & BRIGHTLIGHT retention strategy & Context \\
\hline $\begin{array}{l}\text { Accurate contact information (including } \\
\text { information in order to be able to trace } \\
\text { participants) }[21,24,27,28]\end{array}$ & $\begin{array}{l}\text { Requests for change of address in newsletters; } \\
\text { updated information requested at the end of } \\
\text { each survey; requests from primary/secondary } \\
\text { care providers, easily accessible 'contact us' } \\
\text { information on public facing website with } \\
\text { multiple modes of communication. }\end{array}$ & $\begin{array}{l}\text { Young people are a particularly mobile } \\
\text { population. They are likely to move more than } \\
\text { once during the three years as they progress to } \\
\text { survivorship. }\end{array}$ \\
\hline $\begin{array}{l}\text { Study specific logo (involving participants in logo } \\
\text { development) }[21,25,29]\end{array}$ & $\begin{array}{l}\text { Young people branded the study [15] and all } \\
\text { communication material has logo }\end{array}$ & $\begin{array}{l}\text { Young people will have been exposed to a } \\
\text { number of stakeholders during their cancer } \\
\text { timeline and we wanted ensure an easily } \\
\text { identifiable logo to enable them to remember } \\
\text { they study and have a sense of belonging. }\end{array}$ \\
\hline $\begin{array}{l}\text { Send newsletters, holiday and birthday cards } \\
{[14,21,23,24,27]}\end{array}$ & $\begin{array}{l}\text { Regular newsletters emailed to the Cohort } \\
\text { giving update on study progress; postcards with } \\
\text { emerging findings sent prior to next wave of } \\
\text { participation }\end{array}$ & $\begin{array}{l}\text { Delivering results back to patients and celebratory } \\
\text { e-cards served as a thank you for their } \\
\text { participation. Also gives sense of the study giving } \\
\text { back so that contact is not just for data collection. }\end{array}$ \\
\hline $\begin{array}{l}\text { Monetary incentives/tokens of appreciation [14, } \\
21,22,24,25,27,29,30]\end{array}$ & $\begin{array}{l}\text { Monetary incentives not permitted so } \\
\text { wristbands colour-specific to each wave sent as } \\
\text { thanks for participating (Figure } 1 \text { ). }\end{array}$ & $\begin{array}{l}\text { Young people told us they liked 'free things' and } \\
\text { 'anything would do'. The study was opened the } \\
\text { year of the Olympics so young people suggested } \\
\text { offering bands as medals ie Bronze, silver, and } \\
\text { gold. We chose coloured bands representing our } \\
\text { logo with the fifth final band being a combination } \\
\text { of all four colours. Figure } 1\end{array}$ \\
\hline $\begin{array}{l}\text { Contact with study dedicated staff/building a } \\
\text { relationship }[14,21-25,27]\end{array}$ & $\begin{array}{l}\text { Employ a Cohort Manager responsible for } \\
\text { engaging young people, researchers have } \\
\text { visible face on website and also twitter feeds } \\
\text { contains photos of research team at various } \\
\text { meetings and workshops. }\end{array}$ & $\begin{array}{l}\text { Continuity in care and research is important for } \\
\text { establishing relationships with participants and } \\
\text { employing a person specifically to do this meant } \\
\text { young people always had a specific name to } \\
\text { contact. }\end{array}$ \\
\hline $\begin{array}{l}\text { Send reminders prior to appointment/next wave } \\
\text { of participation }[22,24,27,29,31]\end{array}$ & Ipsos MORI ${ }^{1}$ send letters prior to each wave. & $\begin{array}{l}\text { Young people are known for being busy and may } \\
\text { not prioritised scheduled health related }\end{array}$ \\
\hline
\end{tabular}




\begin{tabular}{|c|c|c|}
\hline & & $\begin{array}{l}\text { appointment particular as they move into } \\
\text { survivorship. Letters remind them of the study } \\
\text { and their participation. }\end{array}$ \\
\hline $\begin{array}{l}\text { Have multiple options for data collection }[14,22 \text {, } \\
25]\end{array}$ & $\begin{array}{l}\text { Waves } 2 \text { to } 5 \text { have the option of online or } \\
\text { telephone interviewer administered survey }\end{array}$ & $\begin{array}{l}\text { During feasibility work, young people told us that } \\
\text { after face-to-face interview their preference } \\
\text { would be online or telephone interviews } \\
\text { therefore we provided both options. }\end{array}$ \\
\hline $\begin{array}{l}\text { Obtain stable contact details (anchoring } \\
\text { contacts) }[14,24,27]\end{array}$ & Stable contact details were obtained at wave 1 & $\begin{array}{l}\text { Young people are a mobile population and } \\
\text { therefore we requested a stable contact who } \\
\text { would be most likely to know where young } \\
\text { people were throughout the study. }\end{array}$ \\
\hline Flexibility in participation $[23,25,29]$ & $\begin{array}{l}\text { At waves } 2 \text { and } 3 \text { young people have a } 2 \text {-month } \\
\text { window to complete the survey; and a } 4 \text {-month } \\
\text { window at waves } 4 \text { and } 5 \text {. Young people can } \\
\text { continue to participate even if they have } \\
\text { missed a wave of data collection. }\end{array}$ & $\begin{array}{l}\text { Young people may not be able to complete all } \\
\text { waves due to health or competing priorities such } \\
\text { as exams/work or may not want to revisit } \\
\text { anything to do with their cancer timeline during } \\
\text { recovery. We allowed flexibility as long as young } \\
\text { people completed wave } 1 \text {. }\end{array}$ \\
\hline $\begin{array}{l}\text { Certificates of participation and thank you cards } \\
{[24,25]}\end{array}$ & $\begin{array}{l}\text { Thank you letters are sent after every wave of } \\
\text { participation and certificates are sent at waves } \\
3 \text {. }\end{array}$ & $\begin{array}{l}\text { We offered certificates as recognition for time } \\
\text { and effort taken to complete surveys. We also } \\
\text { know that young people may be building } \\
\text { portfolios for submission to education or work } \\
\text { and this allows them to demonstrate something } \\
\text { constructive from their illness. }\end{array}$ \\
\hline Have a study dedicated phone number [29] & $\begin{array}{l}\text { BRIGHTLIGHT has a study-specific mobile } \\
\text { number and email address; Ipsos MORI provide } \\
\text { a survey-specific Freephone number }\end{array}$ & $\begin{array}{l}\text { We wanted allow young people and } \\
\text { parents/carers/healthcare professionals direct } \\
\text { access to the research team at all times to answer } \\
\text { any queries related to their participation in the } \\
\text { study, change of contact details. }\end{array}$ \\
\hline
\end{tabular}


Table 2: Example questions similar to those asked in a stakeholder meeting*

\begin{tabular}{|l|l|}
\hline \multicolumn{1}{|c|}{ Questions } & Learning objective for young people \\
\hline $\begin{array}{l}\text { BRIGHTLIGHT team, you said in your } \\
\text { application that you worked with young } \\
\text { people - can you tell us a bit about that? }\end{array}$ & $\begin{array}{l}\text { To show the YAP why the study team involve } \\
\text { young people in research }\end{array}$ \\
\hline $\begin{array}{l}\text { So, team BRIGHTLIGHT, last time we } \\
\text { spoke there were some problems with } \\
\text { recruitment. Would you like to tell us } \\
\text { where you have got to with that? }\end{array}$ & $\begin{array}{l}\text { To expose the challenges the study team } \\
\text { have encountered and how the YAP helped } \\
\text { to overcome them }\end{array}$ \\
$\begin{array}{l}\text { Are all of the young people taking part in } \\
\text { the surveys? }\end{array}$ & $\begin{array}{l}\text { To disclose the issue of retention at wave } 3 \\
\text { and to introduce the aims of the current } \\
\text { workshop }\end{array}$ \\
\hline
\end{tabular}

*The stakeholder is the funder of BRIGHTLIGHT: The National Institute for Health Research YAP: Young Advisory Panel, the BRIGHTLIGHT patient user group 
Table 3: $\quad$ Patient insight into barriers for survey participation, reasons for survey participation and suggested solutions

\begin{tabular}{|c|c|c|}
\hline Barriers to survey participation & Reasons for survey participation & $\begin{array}{l}\text { Solutions to encourage } \\
\text { participation }\end{array}$ \\
\hline $\begin{array}{l}\text { Life commitments: } \\
\text { Better things to do } \\
\text { Other commitments (studies) } \\
\text { Changing job } \\
\text { School or work } \\
\text { Not priority }\end{array}$ & $\begin{array}{l}\text { Altruism } \\
\text { Helping others } \\
\text { Making a difference and enabling } \\
\text { others to be helped } \\
\text { Give back to the cancer community } \\
\text { Prevent others having a bad } \\
\text { experience }\end{array}$ & $\begin{array}{l}\text { Increase/better communication } \\
\text { Remind them it doesn't take long } \\
\text { and quite easy } \\
\text { Remind them it's not a big } \\
\text { investment of time } \\
\text { Text message/email before each } \\
\text { survey - check preferred method }\end{array}$ \\
\hline $\begin{array}{l}\text { Study specific concerns: } \\
\text { No rewards } \\
\text { Frustration at answering the } \\
\text { same question } \\
\text { Amount of time it takes to } \\
\text { answer the question } \\
\text { Long list of answers to choose } \\
\text { from } \\
\text { Time consuming } \\
\text { No incentive } \\
\text { Lack of proper explanation } \\
\text { from social worker etc. }\end{array}$ & $\begin{array}{l}\text { Self-achievement } \\
\text { Sense of completion } \\
\text { Commitment }\end{array}$ & $\begin{array}{l}\text { Study specific } \\
\text { Be flexible with when it can be } \\
\text { completed } \\
\text { Less paper- all information } \\
\text { consolidated in one place- e.g. } \\
\text { an app } \\
\text { Break online version into } \\
\text { modules-option to save and } \\
\text { return to complete later. } \\
\text { Rewards- group outings, prize } \\
\text { draws }\end{array}$ \\
\hline $\begin{array}{l}\text { Emotional barriers: } \\
\text { Personal issues } \\
\text { Sensitive topics } \\
\text { Unwillingness to revisit } \\
\text { experience of cancer } \\
\text { Too personal/ emotional } \\
\text { Not wanting to talk about } \\
\text { issues }\end{array}$ & $\begin{array}{l}\text { Having a voice/being heard } \\
\text { Being heard }\end{array}$ & $\begin{array}{l}\text { Incentives } \\
\text { Short, sharp information on } \\
\text { what's involved in the surveys: } \\
\text { it's not all about cancer }\end{array}$ \\
\hline $\begin{array}{l}\text { Practical barriers: } \\
\text { Moving house } \\
\text { Changing mobile tel[ephone] } \\
\text { number } \\
\text { Change in contact details }\end{array}$ & $\begin{array}{l}\text { Rewards } \\
\text { Make info more concise short and } \\
\text { interesting } \\
\text { Updates on Twitter } \\
\text { Rewards days out }\end{array}$ & $\begin{array}{l}\text { Freepost envelope to inform } \\
\text { study team of change of address }\end{array}$ \\
\hline $\begin{array}{l}\text { Other reasons : } \\
\text { Forgetting } \\
\text { Memory } \\
\text { Decline in health } \\
\text { Difficult to remember details } \\
\text { from first being diagnosed }\end{array}$ & & \\
\hline
\end{tabular}


Box 1: Question prompts for the young people to consider when discussing the BRIGHTLIGHT website

Why do you use the website?

Features to make you go on the website?

Do you use on your phone, or laptop? 
Box 2: Summary of changes made to optimise retention

- Enhanced method of tracing young people

- Revised website including information about the study team, photographs of previous workshops, publications, conference presentations and posters (http://www.brightlightstudy.com/).

- Infographic postcard with key emerging findings sent to participants prior to each wave (Figure 4)

- Personalised letter to participants prior to Wave 5 survey to reinforce the value the study team place on their participation.

- Additional guidance to the telephone interviewers in their introductory script to emphasise that if young people were not on treatment they would not be asked questions specific to cancer. 
Box 3 Recommendations for retaining young people in a cohort study.

1. Identify a centralised, robust mechanism at study onset for tracing young people and getting accurate contact details. This is the only way to ensure young people are kept informed and reminded of subsequent participation.

2. Ensure a member of the research team is astute with advances in technology and the social media landscape, ideally employing a member of the team in a communication/engagement role.

3. Consider implementing some/all the measures outlined in Table 1. 


\section{Figure 1: $\quad$ BRIGHTLIGHT wristband 'reward' for participation}

Young people were rewarded with BRIGHTLIGHT wristbands following completion of each wave of data collection (Photo produced with permission from James Shaw) 
Figure 2a: Bridge poster activity 
Figure 2b: Photo of completed bridge 
Figure 3: Question from the online survey to gather independent reflections of the 3 most suitable solutions to retention 
Figure 4: $\quad$ Example of a postcard sent to young people containing emerging results 